\title{
Reactive Power Compensation of Distribution Networks with Unified Power Quality Conditioner Using Multi-Objective Particle Swarm Optimization
}

\author{
K.Pavani $^{1}$, Dr.A.Lakshmi Devi ${ }^{2}$ \\ PG Student [ICS], Dept. of EEE, SV University, Tirupati, A.P ${ }^{1}$ \\ Professor, Department of EEE, SV University, Tirupati, A.P ${ }^{2}$
}

\begin{abstract}
This paper presents a study on the impact of unified power-quality conditioner (UPQC) allocation on radial distribution systems. A UPQC consists of a series and a shunt inverter. In UPQC, the series inverter injects a voltage with controllable phase angle in such a way that the voltage magnitude at load end remains unchanged. Due to the phase angle shift, the series inverter participates in load reactive power compensation along with the shunt inverter during healthy operating condition. In the proposed approach, the optimal design parameters of UPQC are determined by minimizing objective functions network power loss, Percentage of Nodes with Under Voltage Problem(PNUVP).These objectives are simultaneously minimized to obtain a set of non-dominated solutions using multi-objective PSO (MOPSO). The results show that a significant amount of power-loss reduction, under voltage mitigation can be obtained with an appropriate placement of the UPQC in a distribution network. The performances of PSO with UPQC and UPQC with Capacitor variants are compared and the better one is used in all subsequent studies.
\end{abstract}

Keywords: Capacitor, Multi-objective planning, PNUVP, Power loss, Unified Power Quality Conditioner (UPQC), Voltage profile.

\section{INTRODUCTION}

Reactive power compensation is an important issue in electric power systems, involving operational, economical and quality of service aspects. Consumer loads (residential, industrial, service sector, etc.) impose active and reactive power demand, depending on their characteristics. Active power is converted into "useful" energy, such as light or heat. Reactive power must be compensated to guarantee an efficient delivery of active power to loads, thus releasing system capacity, reducing system losses, and improving system power factor and bus voltage profile. Thus Optimal reactive power compensation can significantly improve the performance of a radial distribution network. There are several reactive power compensation strategies reported time-to-time in the literature, for example capacitor placement [11], [12].The latest addition is the distribution FACTS (DFACTS) device allocation. Although DFACTS devices are traditionally used in power quality improvement they can be used in optimal reactive power compensation as well. In [6], the optimal allocation of Capacitor is carried out to minimize network power loss and to improve node voltage magnitude. The unified power quality conditioner (UPQC) is one of the versatile DFACTS devices [4]. The research on UPQC is mostly focused on the mitigation of power quality problems for single load [4]-[5]. The theme of this paper is set as an investigation of its potential applicability in optimal reactive power compensation of a distribution network.

The UPQC is a combination of series and shunt active filters connected in cascade via a common DC link capacitor. The main purpose of a UPQC is to compensate for supply voltage power quality issues such as sags, swells, unbalance, flicker, harmonics, and for load current power quality problems such as, harmonics, unbalance, reactive current and neutral current. With the two inverters, a UPQC can protect a customer/load from sag, swell in supply voltage, and it can also reduce the harmonic pollution created by the load. The shunt inverter injects a shunt compensating current to the load in order to provide load reactive compensation and to compensate the harmonic distortion created by the load. The series inverter is used to mitigate voltage-related problems, for example, sag and swell in supply voltage, etc. Basically, it injects a series voltage to the load. The series inverter only provides active power in UPQC-P and reactive power in UPQC-Q by injecting a controllable in-phase and a controllable quadrature voltage, respectively so as to mitigate voltage sag problem. A comparative performance assessment of these two models is given in [13]. The series inverter in UPQC-S can simultaneously provide both real and reactive powers [5].

A modified design of the phase angle control model for UPQC (UPQC-PAC)[15] is proposed in this work. In the UPQC-PAC, the series inverter injects a controllable series voltage so as to shift the phase angle of the load voltage.

Due to this phase shift, the series inverter participates in load-reactive power compensation along with the shunt inverter and helps in reduction of the VA rating of the shunt inverter. In [14], UPQC is modelled for the reactive power compensation of a single load. Thus, its design is slightly modified so that a UPQC can be capable of providing the reactive power compensation of a distribution network

To determine the optimal location and parameters of UPQC, planning model is formulated with objective 
functions. They are minimization of: 1) network power voltage and the shunt inverter absorbs the current loss 2) percentage of nodes with undervoltage problem harmonics generated by the load. The DC/DC converter (PNUVP). The simultaneous optimization of these objectives is carried out using Pareto-dominance principle to obtain a set of non-dominated solutions called Paretoapproximation set, in which no solution is inferior to other. The solution strategy used is particle swarm optimization (PSO) for its easy implementation, effective memory use, and an efficient maintenance of the solution diversity. Its performance is also tested on a number of power system problems . Since PSO is a multi-point search algorithm, it can provide a set of non-dominated solutions in a single run. Their performances on the present problem are compared and the better one is used in subsequent studies. The planning approach is validated on a 33-node distribution networks. Different case studies are carried out and the results are analyzed. The results obtained with the proposed algorithm are found to be better as compared to the approaches reported in [6].

\section{BASIC CONFIGURATION OF UPQC}

UPQC is the integration of series and shunt active power filters, connected back-to-back on the dc side, sharing a common DC capacitor, shown in Fig.3. The series component of the UPQC is responsible for mitigation of the supply side disturbances: voltage sags/swells, flicker, voltage unbalance and harmonics. It inserts voltages so as to maintain the load voltages at a desired level; balanced and distortion free. The shunt component is responsible for mitigating the current quality problems caused by the consumer. Basic functional lock diagram of UPQC is shown in fig 1 .

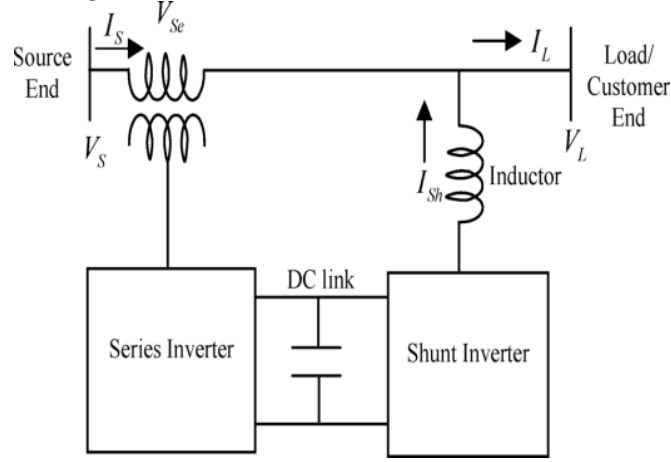

Fig.1.Basic schematic of UPQC works in charge mode or standby mode depending on the voltage level of the super capacitors. In voltage sag or swell mode, the series inverter injects the compensating voltage to maintain the load voltage constant. The shunt inverter absorbs the current harmonics generated by the load and the DC/DC converter works in standby mode. In voltage interruption mode, the series inverter is disconnected from the line and the circuit breaker is opened to isolate the source side. The shunt inverter starts to work as an AC voltage source. Phasor diagram of shunt and series shunt and series compensations are shown in Fig. 2.

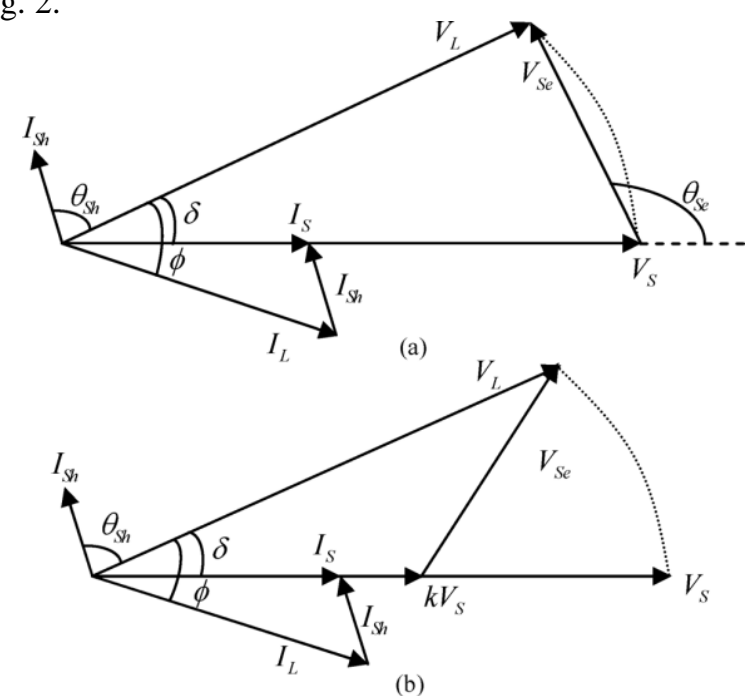

Fig.2. Phasor diagram of shunt and series compensations of UPQC operating (a) at normal/healthy condition and (b) at voltage sag

\section{MULTI-OBJECTIVE PLANNING MODEL FOR REACTIVE POWER COMPENSATION WITH UPQC ALLOCATIONS}

In the proposed planning approach, a multi-objective planning model is formulated to determine the optimal location for UPQC, the optimal amount of reactive power compensation required at the location. These optimizing variables are determined by minimizing objective functions. They are 1) Network power loss 2) Voltage profile improvement 3) Percentage of nodes with undervoltage problem(PNUVP).These objectives deals with the performance of network. The minimization of these objectives is required to obtain better performance a network. The expressions for these objective functions are given as follows:

Objective function 1: $P_{\text {Loss }}^{U P Q C}=\Sigma\left\{I_{L}^{2}\right\}(R)$ Objective function 3: $P N U V P=100\left(\mathrm{~N}_{\mathrm{UPQC}}{ }^{\mathrm{UV}} / \mathrm{N}_{\text {Base }}{ }^{\mathrm{UV}}\right)$

where $I_{L}$ represent line current and $\mathrm{R}$ represent resistance of the branch. The set consists of all branches in a network. $\mathrm{N}_{\mathrm{UPQC}}$ UV and $\mathrm{N}_{\text {Base }}$ UV represent number of nodes with under voltage problem with and without UPQC allocations, respectively. Basically, the denominator of the objective function 3 is used to understand the degree of undervoltage mitigation taking place due to the UPQC allocation. 
The optimization is carried out under the following Constraints:

1) A UPQC is designed so that it can mitigate a given maximum value of voltage sag, if required.

2) The total reactive power delivered by a UPQC is to be kept below the sum of the reactive power demand of all nodes in a network, i.e.,

$$
0<\mathrm{Q}_{\mathrm{UPQC}} \leq \sum_{j=1}^{N} Q_{L}(\mathrm{j})
$$

Each node except the substation node is considered as a candidate node for the UPQC allocation. Finally, a solution can be selected from the set according to the requirement and investment budget of a utility. For example, if a utility desires to implement the solution corresponding to the lowest power loss its investment becomes the highest because the MVA rating for the solution is highest. There are different multi-objective optimization approaches for example weighted aggregation, Pareto-based approach, lexicographic ordering etc. In this work, the Pareto based approach is used.

\subsection{Pareto-Dominance Principle}

The Pareto-dominance principle states that, for an Mobjective optimization (say, minimization) problem, a solution is said to dominate another solution if

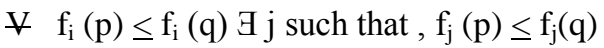

Where $f_{i} / i=1 \ldots M$ are the objective functions. The set of the optimal non-dominated solutions are called Pareto-optimal set.

\section{MULTI-OBJECTIVE PLANNING ALGORITHM FOR REACTIVE POWER COMPENSATION USING PSO}

In this section, the planning algorithm is provided in detail along with the brief discussion on MOPSO.

\subsection{PSO: A brief overview}

PSO is a population-based multi-point search technique that mimics the social behaviour of a flock of birds and a fish school. The search starts with a population of search points called particles. Each particle is encoded by a position vector(X), containing multi-dimensional information (initially chosen at random), which is updated by using particle's velocity (initially chosen at random) in successive iterations. The velocity vector (V) of a particle is updated using its own previous best position (Pbest) and the best neighbourhood particle's position (nbest ).

Compared with traditional optimization algorithms, PSO does not need the information of the derivative of the functions. Unlike classical optimization techniques, such as gradient search methods, the PSO-based optimization does not get stuck up at local minima but will always converge to a global minimum, if at all it exists. This algorithm can work as long as the fitness values for the optimization model can be calculated. Compared with the genetic algorithm, the advantage of the PSO is that it is very simple in terms of mathematical expression and understanding. Further, the PSO algorithm is faster in converging to a solution when compared to genetic algorithms (GAs) because of its mathematical simplicity.
Due to the aforementioned advantages, the PSO-based technique has been used for UPQC.

\subsection{MOPSO: A Brief Overview}

MOPSO is a version of PSO to solve multi objective optimization problems, in which a particle has multiple fitness values. There are many MOPSO variants and the state-of-the-art review can be obtained in [1]. Most of the approaches belong to the Pareto-dominance based approaches. The main goals of all these approaches are to obtain a set of non-dominated solutions closer to the set of the Pareto-optimal solutions (i.e., better Convergence) and to get diversified solutions (i.e., better diversity among the solutions). Better convergence can be achieved by the selection of proper guide for each particle. NSMOPSO is inspired from the philosophy of non-dominated sorting genetic algorithm-II [26]. In NSMOPSO, the nondominated solutions are determined from the population members of the current iteration and the previous iteration. Then, all nondominated solutions are sorted according to niche mechanism [22].A set of the guides is formed using a given number of better ranked solutions. In any iteration, a particle randomly selects its own guide from the set of the guides.

\subsection{Planning algorithm:}

Begin

$/ / \eta_{\text {pop }}$ Size of population

$/ / \eta_{\text {gen }}=$ Maximum number of iterations

Generate initial population using encoding scheme (both position and velocity)

Decode the particles and calculate objective functions

Find the initial non dominated solutions

Find out initial set of guides

teration $=1$;

While iteration $<=\eta_{\text {gen }}$

For $i=1 \ldots \eta_{\text {gen }}$

Assign guide for particle i from set of guides

Update velocity and position of particle;

Decode particle to get parameters of UPQC;

Perform load flow using UPQC model;

Calculate the objective functions;

\section{End for}

Find out non dominated solutions;

Find out the new set of guides

Iteration $=$ iteration +1

\section{End while}

The final set of non dominated solution consists of optimal location and parameters of UPQC

\section{End}

The planning algorithm consists of two important support subroutines, i.e., particle encoding/decoding scheme and load flow with UPQC model. A particle in MOPSO consists of three segments with the direct information of: 1) UPQC location in the network, 2) the amount of reactive power compensation required.During the decoding process, the first segment of a particle is always converted to its nearest integer number. The solutions violating constraints are penalized. The pseudo codes for the complete planning algorithm are shown in 4.3 . 


\section{RESULTS AND DISCUSSIONS}

A simulation study is performed to validate the proposed planning approach using two test distribution network of 33-node and system. The system data are available in [16], respectively. Both the systems have one substation located at node 1 and all other nodes are load nodes. The optimal reactive power compensation is determined considering the peak load demand at each node. The MOPSO parameters are optimized using repetitive runs.

\subsection{Impact Of Network Power Loss Using UPQC:}

The effect of network power loss due to the UPQC allocation at different nodes is shown in Fig 3 and Fig 4 for the two test systems. The power losses of the network without UPQC and with UPQC are $202.67 \mathrm{KW}$ and 145.72 KW for the 33-node. Location of UPQC is at node 17. The result shows that substantial loss reduction can be achieved with UPQC if it is properly designed and suitably located in the network. This happens due to the load reactive power compensation provided by the UPQC.A UPQC designed to mitigate a higher amount of voltage sag provides better reactive power compensation. The solutions corresponding to the lowest power loss obtained with the UPQC for 33 bus system.

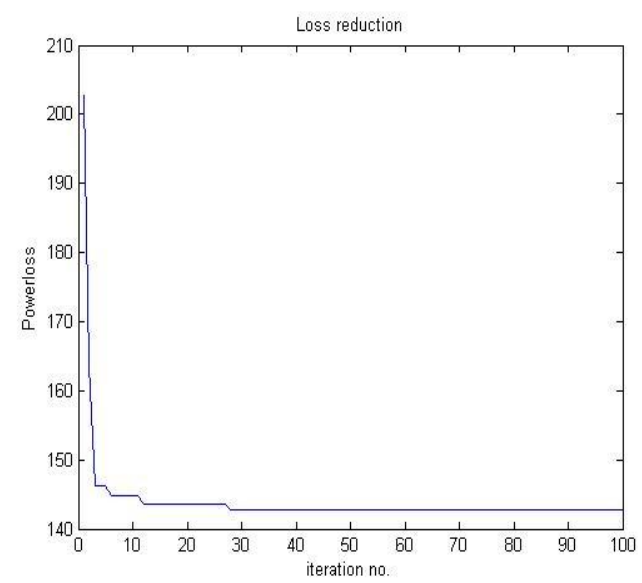

Fig:3 Power loss reduction using UPQC

5.2 Impact of under voltage mitigation using UPQC:

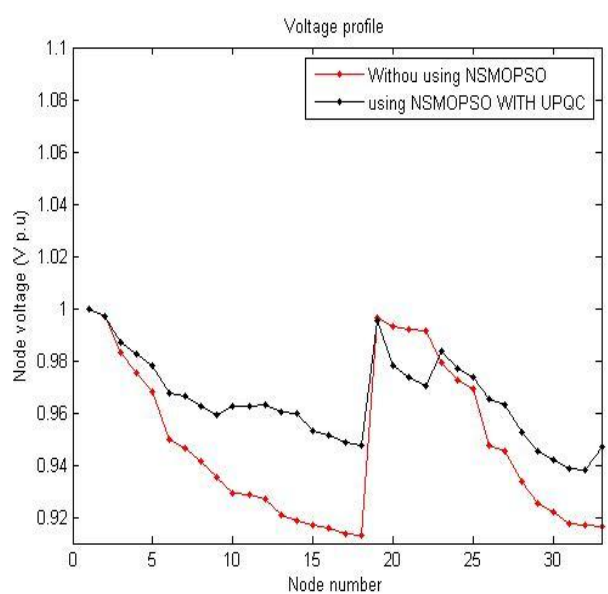

Fig.4 Voltage profile for 33-bus system with and without using UPQC

A UPQC can efficiently be used in under voltage mitigation if it is used in healthy operating conditions as shown in [15]. In this paper, the upper and lower voltage limits are set to be 1 p.u. and 0.95 p.u respectively. If the voltage at any node is less than the lower limit, it is said that it suffers from the under voltage problem. In the 33node system, 21 out of 33 nodes (i.e., 63.63\%) have an under voltage problem without UPQC. By using UPQC only 9 out of 33 nodes are only suffering from under voltage problem $(27.27 \%)$. Voltage profile improvement with and without using UPQC is shown in Fig.4

5.3. Performance comparison with reactive power compensation using UPQC and CAPACITOR allocation:

The work is focussed on reactive power compensation of radial distribution network using UPQC. A quantitative performance comparison is done for voltage profile using UPQC and only with Capacitor and UPQC with Capacitor for 33 bus system. Capacitor is placed at node 11. A better solution in terms of node voltage is obtained with the UPQC and capacitor than only with UPQC.

The result shows that Voltage profile is considerably improved by placing Capacitor in combination with UPQC. Comparison is also made for the Percentage of Nodes with Undervoltage Problem (PNUVP) and it is reduced by using Capacitor placed with UPQC. Better solutions are obtained and no node is suffering from undervoltage problem after placing Capacitor with UPQC.

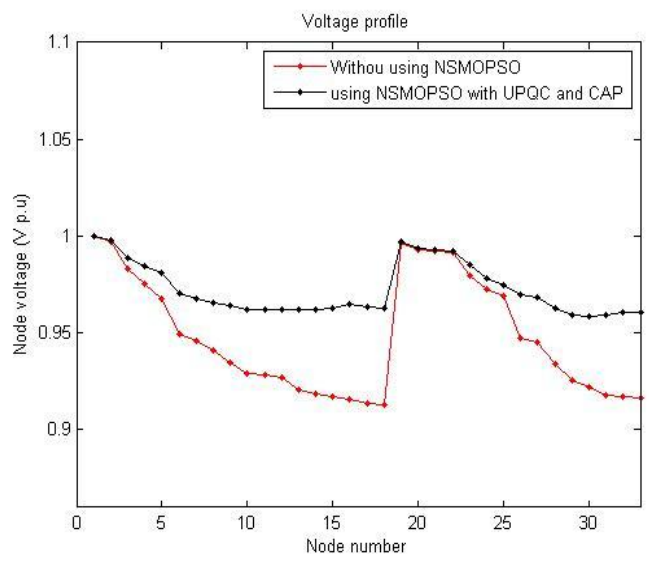

Fig.5 Voltage profile by using UPQC and Capacitor

\subsection{Performance comparison with Capacitor allocation:}

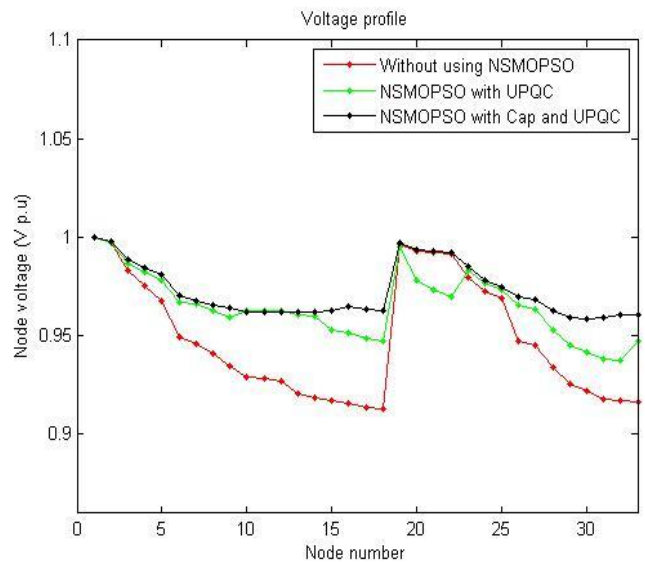

Fig.6.Comparion of Voltage profile with and without using capacitor with UPQC 
INTERNATIONAL JOURNAL OF INNOVATIVE RESEARCH IN ELECTRICAL, ELECTRONICS, INSTRUMENTATION AND CONTROL ENGINEERING Vol. 3, Issue 12, December 2015

\begin{tabular}{|l|l|l|l|}
\hline Parameters & $\begin{array}{l}\text { Base } \\
\text { case }\end{array}$ & $\begin{array}{l}\text { With } \\
\text { UPQC }\end{array}$ & $\begin{array}{l}\text { With } \\
\text { UPQC \& } \\
\text { Capacitor }\end{array}$ \\
\hline Power loss(KW) & 202.7 & 145.72 & 145.72 \\
\hline $\begin{array}{l}\text { Minimum voltage } \\
\left(\mathrm{V}_{\text {min }}\right)(\mathrm{p.u})\end{array}$ & 0.9130 & 0.9419 & 0.9585 \\
\hline $\begin{array}{l}\text { Percentage of } \\
\text { Nodes with Under } \\
\text { Voltage Problem } \\
\text { (PNUVP) }\end{array}$ & $63.63 \%$ & $27.27 \%$ & 0 \\
\hline
\end{tabular}

\section{CONCLUSION}

An investigative study has been carried out to bring out the impact of the UPQC allocation on distribution systems. A new design approach for UPQC to mitigate a given value of voltage sag is proposed. A multi-objective planning for the reactive power compensation of radial distribution networks with UPQC allocation has been reported. In the proposed planning approach, the optimal location, the optimal reactive power compensation required at the location are determined. The UPQC model is suitably modified so as to provide the reactive power compensation of a distribution network. Both the inverters participate in the reactive power compensation. The UPQC model is suitably incorporated into the load flow algorithm of distribution systems. UPQC is optimally allocated and operated at healthy operating condition it can significantly reduce the power loss and improve the node voltage of a distribution network. The quantitative performance comparison shows that better solutions are obtained with the UPQC and Capacitor when compared to [1].

The allocation of UPQC can easily be done by changing the particle encoding of the algorithm. Some more features of UPQC can be incorporated into the planning model, for example voltage stability limit, line loadability, and load balancing. This needs future investigations.

\section{REFERENCES}

1) Sanjib Ganguly," Multi-Objective Planning for Reactive Power Compensation of Radial Distribution Networks With Unified Power Quality Conditioner Allocation Using Particle Swarm Optimization", IEEE TRANSACTIONS ON POWER SYSTEMS, VOL. 29, NO. 4, JULY 2014

2) Sanjib Ganguly, "Impact of Unified Power-Quality Conditioner Allocation on Line Loading, Losses, and Voltage Stability of Radial Distribution Systems", IEEE TRANSACTIONS ON POWER DELIVERY, VOL. 29, NO. 4, AUGUST 2014.

3) Srinivas Bhaskar Karanki, Mahesh K. Mishra, Senior Member, IEEE, and B. Kalyan Kumar,,"Particle Swarm Optimization-Based Feedback Controller for Unified Power-Quality Conditioner", IEEE TRANSACTIONS ON POWER DELIVERY, VOL. 25, NO. 4, OCTOBER 2010

4) V. Khadkikar, "Enhancing electric power quality using UPQC: A comprehensive overview," IEEE Trans. Power Electron., vol. 27, no. 5, pp. 2284-2297, May 2012.

5) V. Khadkikar and A. Chandra, "UPQC-S: A novel concept of simultaneous voltage sag/swell and load reactive power compensations utilizing series inverter of UPQC," IEEE Trans. Power Electron., vol. 26, no. 9, pp. 2414-2425, 2011.

6) A. Ghosh and G. Ledwich, "A unified power quality conditioner (UPQC) for simultaneous voltage and current compensation," Elect. Power Syst. Res., vol. 59, no. 1, pp. 55-63, Aug. 2001.

7) H. Fujita and H. Akagi, "The unified power quality conditioner: The integration of series active filters and shunt active filters," IEEE Trans. Power Electron., vol. 13, no. 2, pp. 315-322, Mar. 1998.
8) V. Khadkikar and A. Chandra, "A novel structure for three-phase fourwire distribution system utilizing unified power quality conditioner (UPQC)," IEEE Trans. Ind. Applicat., vol. 45, no. 5, pp. 1897-1902, 2009

9) A. Jindal, A. Ghosh, and A. Joshi, "Interline unified power quality conditioner," IEEE Trans. Power Del., vol. 22, no. 1, pp. 364-372, Jan. 2007.

10) M. Brenna, R. Faranda, and E. Tironi, "A new proposal for power quality and custom power improvement: OPEN UPQC," IEEE Trans. Power Del., vol. 24, no. 4, pp. 2107-2116, Oct. 2009.

11) D. Das, "Reactive power compensation for radial distribution networks using genetic algorithm," Int. J. Elect. Power Energy Syst., vol. 24, pp. 573-581, 2002.

12) M. Chis,M. Salama, and S. Jayaram, "Capacitor placement in distribution systems using heuristic search strategies," Proc. Inst. Elect. Eng., Gener., Transm., Distrib., vol. 144, no. 3, pp. 225-230, 1997.

13) M. Basu, S. P. Das, and G. K. Dubey, "Comparative evaluation of two models of UPQC for suitable interface to enhance power quality," Elect. Power Syst. Res., vol. 77, pp. 821-830, 2007.

14) V. Khadkikar and A. Chandra, "A new control philosophy for a unified power quality conditioner (UPQC) to coordinate loadreactive power demand between shunt and series inverters," IEEE Trans. Power Del.,vol. 23, no. 4, pp. 2522-2534, Oct. 2008.

15) Y. Valle, G. K. Venayagamoorthy, S. Mohagheghi, J. Hernandez, and R. G. Harley, "Particle swarm optimization: Basic concepts, variants and applications in power systems," IEEE Trans. Evol. Computat., vol. 12, no. 2, pp. 171-195, 2008. 